\title{
Stability design of maglev actuator in active vibration control
}

\author{
Yuan $\mathrm{Ni}^{1,2}, \mathrm{He} \mathrm{Lin}^{1,2}$ \& Yan $\mathrm{Li}^{1,2}$ \\ ${ }^{1}$ Institute of Noise \& vibration, Naval University of Engineering, Wuhan, 430033, China \\ ${ }^{2}$ Science and Technology on Ship Vibration and Noise Laboratory, 430033, China
}

Keywords: maglev actuator, stability, active vibration control.

\begin{abstract}
Maglev actuator is widely used in active vibration control. This type of actuator often works in parallel with passive vibration isolator, and they compose a passive-active vibration isolation system. Any vibration isolation system must be stable, so it is necessary to conduct stability design before use. In this paper, the theoretical model is established. Based on the model, the negative stiffness of the actuator is deduced, and the stiffness model of the hybrid system is determined. According to the stiffness criterion, the stable working air gap of a certain maglev actuator is designed.
\end{abstract}

\section{Introduction}

Active vibration control is now well established and successfully applied to many engineering applications as a valid alternative to passive control techniques, especially in the low frequency range[1]. Actuators are key elements in active control system which can affect the control performance directly[2].

Maglev actuator is an actuator with many excellent performances such as large output force, quick response, low power consuming, which is widely used in active vibration control[3]. Daley et al.[4] developed a "smart spring" mounting system in which a Maglev actuator was combined in parallel with passive elements. $\mathrm{He}[5]$ combined the maglev actuator and air spring together and designed a passive-active hybrid vibration isolation mount. In the mount, the air spring supports the weight of the machinery and isolates its broadband vibration and the maglev actuator controls its low frequency vibration, experiment results show that the technology has superiority of low power consumption, good stability and excellent broadband and low frequency vibration control effects.

Passive-active vibration isolation system using maglev actuator is an elastic structure combining positive and negative stiffness. According to the stiffness criterion[6], the system is unstable when the stiffness is negative. Any vibration isolation system must be stable, so it is necessary to conduct stability design before the actuator is used. In this paper, the theoretical model of the actuator is established. Combining the negative stiffness of the actuator with the positive stiffness of the spring, the stiffness model of the hybrid system is determined, hence the stiffness criterion is used to determine the stable working air-gap of a certain maglev actuator.

\section{System model}

\subsection{Theoretical model of maglev actuator}

Maglev actuator often works in parallel with passive vibration elements like spring, air spring, rubber and so on. They compose an passive-active hybrid isolation system, in which the passive elements support the weight of the machinery and isolate the broadband vibration and the maglev actuator controls its low frequency vibration. The hybrid system is shown in Fig. 1 


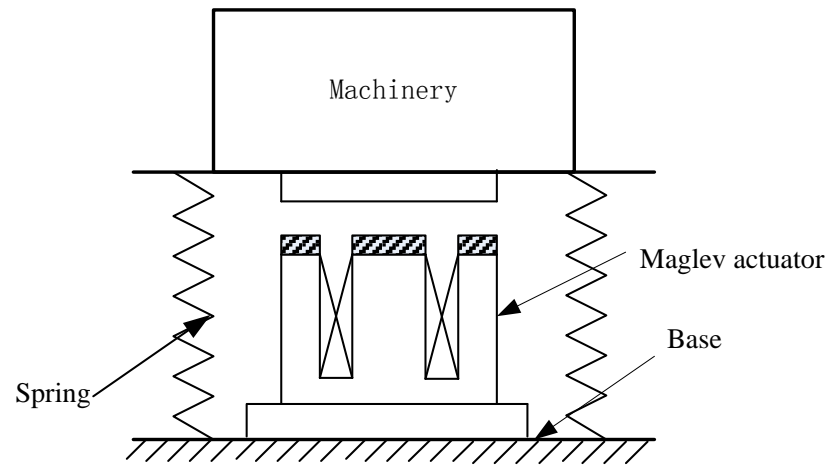

Fig.1: Schematic diagram of the hybrid system

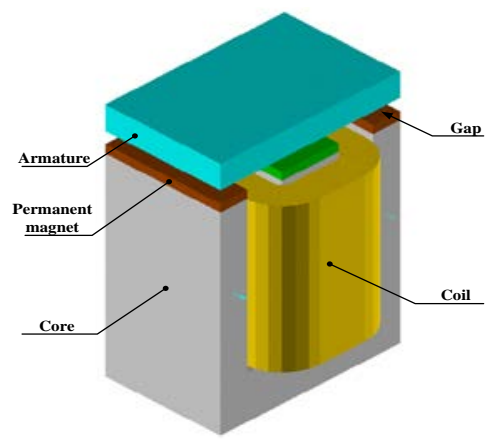

Fig.2: Schematic diagram of maglev actuator

The E type maglev actuator is shown in Fig.2, which is made up of core, armature, permanent magnet and coil. The permanent magnets are attached to top of the core, which generate the bias magnetic flux in magnetic circuit, and the bias force is produced between the permanent magnet and the armature. If current goes through the coil, according to the electromagnetic effect, excitation flux can also be produced in the circuit. Conduct the coil with AC current, then alternating force is produced between the permanent magnet and the armature. Control the AC current, and the alternating force is controlled. So the force genertated by maglev actuator can counteract the force transimitted from machinery to the base, and the vibration is active controlled.

Ignoring the flux leakage and the magnetic resistance of the iron in Fig.2, according to the theories of magnetic circuit, there are[7]:

$$
\left(\frac{g}{\mu_{0} S_{1}}+\frac{g}{\mu_{0} S_{2}}\right) \varphi+\left(\frac{h}{\mu_{0} \mu_{r} S_{1}}+\frac{h}{\mu_{0} \mu_{r} S_{2}}\right) \varphi=N i+F_{m}
$$

and

$$
\varphi=B_{1} S_{1}+B_{2} S_{2}
$$

Where ${ }^{g}$ is the air gap between the permanent magnet and the armature, $h_{\text {is }}$ the thickness of the permanent magnet, $S_{1}$ and $S_{2}$ are respectively the inner and outer face of the core and $B_{1}$ and $B_{2}$ are the magnetic strength. $\mu_{0}$ and $\mu_{r}$ are respectively the relative permeability of free space and the permanent magnet. $\varphi$ is the flux, $F_{m}$ is the magnetic potential generated by the permanent magnets. ${ }^{N}$ and ${ }^{i}$ are respectively the turn of the coil and the current.

According Eqs. (1) and (2), the output force $F$ between permanent magnet and the armature can be written as:

$$
F=-\mu_{0} \frac{S_{1} S_{2}}{S_{1}+S_{2}} \frac{\left(N i+F_{m}\right)^{2}}{\left(g+h / \mu_{r}\right)^{2}}
$$

When there is no control current, the bias force generated by permanent magnet can be written as:

$$
F_{a}=\alpha /(g+\lambda)^{2}
$$

Where

$$
\alpha=-\mu_{0} S_{1} S_{2} F_{m}^{2} / k^{2}\left(S_{1}+S_{2}\right), \lambda=h / k \mu_{r}
$$

\subsection{Stiffness model of the system}

It can be seen from Eq.(4) that the bias force of the actuator is always the attractive force, and it 
increases when air gap decreases, so stiffness of the actuator can be seen as negative.

Differentiate the bias force with the air gap, and the equivalent negative stiffness of the actuator can be written as:

$$
K_{a}=-2 \alpha /(\lambda+g)^{3}
$$

On the assumption that the stiffness of passive spring is Ks, the total stiffness of the parallel system is the sum of the stiffness of the spring and the maglev actuator, which can be written as:

$$
K=K_{a}+K_{s}
$$

According the stiffness criterion, the stability of the hybrid system can be expressed as follows:

i) Stable: $K>0$

ii) Unstable: $K<0$

\section{Stability design of a maglev actuator}

In the model mentioned above, the reluctances of the core and the flux leakage in the magnetic circuit are not considered. The theoretical model is not precise enough and can only be used as electromagnetic force estimation. In this paper, we use curve fitting method to identify the parameters of Eq.(4) according to experiment data of a certain maglev actuator. The results are shown in Fig. 5 and Tab. 1.

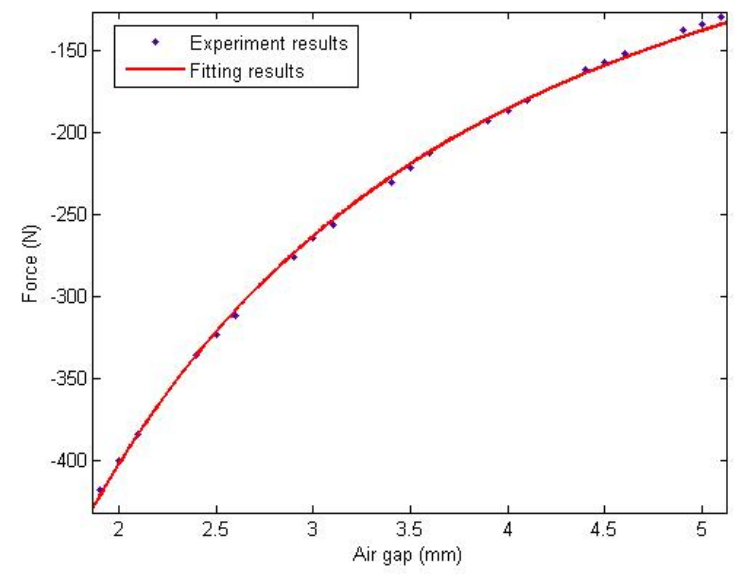

Fig.3: Bias force vs. air gap

Table 1: Identified parameters of the actuator

\begin{tabular}{cc}
\hline Parameters & Fitting results \\
\hline$\alpha$ & -7189 \\
$\lambda$ & 2.226 \\
\hline
\end{tabular}

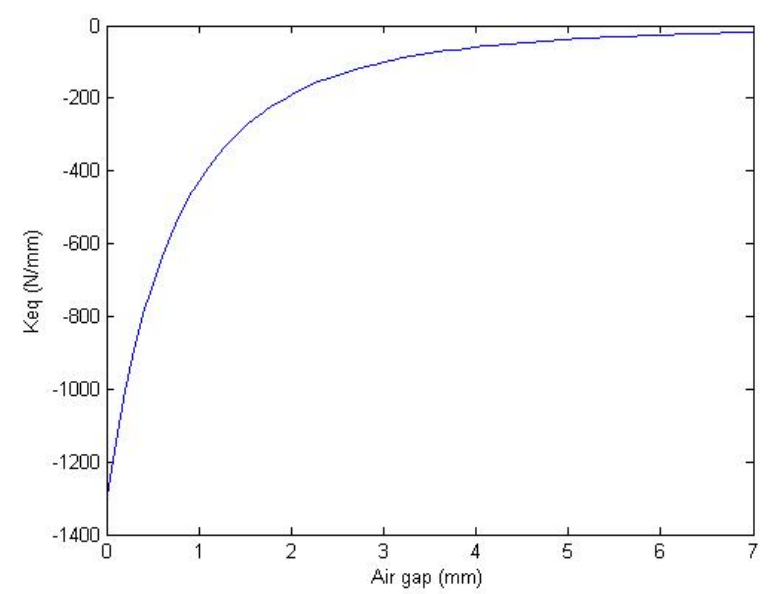

Fig.4: Equivalent negative stiffness vs. air gap

Substituting the identified parameters into Eq.(6), the equivalent negative stiffness against air gap is shown in Fig.4. It can be seen from Fig.4 that the absolute value of the negative stiffness of 
the actuator increases when the air gap decreases.

In this paper, air spring is chosen as the passive elment. The stiffness of the air spring has weak nonlinearity, and it is shown in Fig.5:

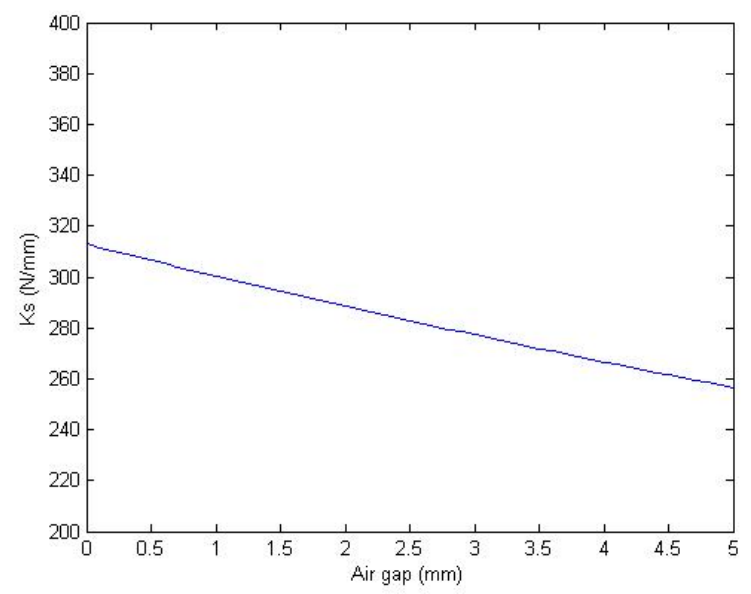

Fig.5: Stiffness of air spring vs. air gap

It can be seen from Fig. 5 that the stiffness of the air spring slightly decreases when the air gap increases. Combining the stiffness of the air spring with the negative stiffness of the maglev actuator, the total stiffness of the system is shown in Fig.6.

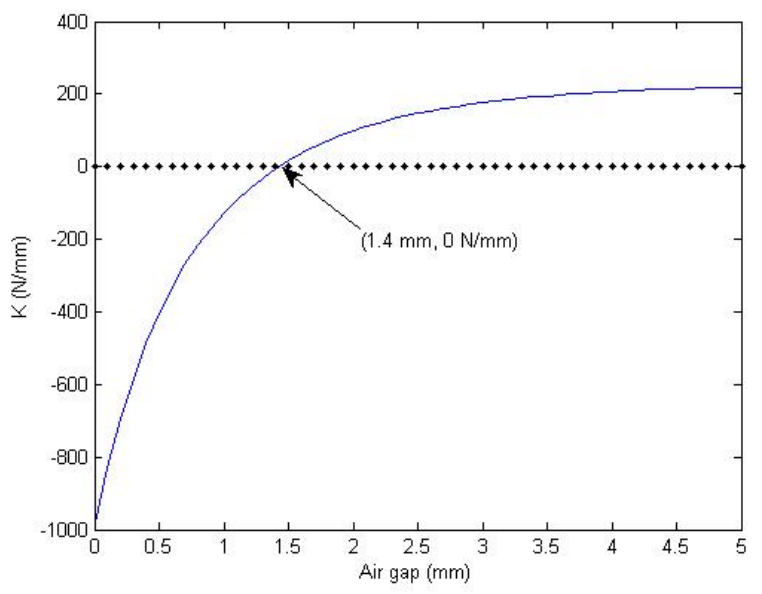

Fig.6: Stiffness of hybrid system vs. air gap

It can be seen from Fig.6 that the total stiffness of the system increases with the air gap. At the air gap of $1.4 \mathrm{~mm}$, the total stiffness of the system is zero. If the air gap is greater than $1.4 \mathrm{~mm}$, the total stiffness is greater than zero, whereas the total stiffness is smaller than zero. According to the stiffness criterion, when the air gap is greater than $1.4 \mathrm{~mm}$, the maglev actuator is stable, whereas the actuator is unstable. So the stable working air gap should be design to be greater than $1.4 \mathrm{~mm}$.

\section{Conclusions}

In this paper, the theoretical model of the maglev actuator is established. Based on the model, the equivalent negative stiffness of the maglev actuator is deduced. Combined with the stiffness of the passive element, the total stiffness of the passive-active hybrid isolation system is established. According to the stiffness criterion, the stable working air gap of a certain maglev actuator is designed to be greater than $1.4 \mathrm{~mm}$.

\section{References}

[1] Fuller, C.R, Elliott, S.J, Nelson, P.A. Active control of Vibration. London: UK, Academic,1997 
[2] Yin Cao, Hong-ling Sun \& Feng-yan An. Active control of low-frequency sound radiation by cylindrical shell with piezoelectric stack force actuators. Journal of Sound and Vibration, 331, pp. 2471-2484,2012

[3] Feng-yan An, Hong-ling Sun \& Xiao-dong Li. Adaptive active control of periodic vibration using maglev actuators. Journal of Sound and Vibration, 331(9), pp.1971-1984,2012

[4] Daley, S., Johnson, F.A., \& Pearson, J.B., Active vibration control for marine applications. Control Engineering Practice, 12, pp.465-474,2004

[5] Lin He, Yan Li \& Jing Tian. Theory and experiment of passive-active hybrid vibration isolation mounts using electromagnetic actuator and air spring. ACTA ACUSTICA, 38(2), pp.241249,2013

[6] Jie-hua Peng. The Stability and Application of A Structure with Positive stiffness Element and Negative Stiffness Element. Journal of Vibration, Measurement \& Diagnosis, 15(2), pp. 14-18, 1995

[7] Yuan Ni, Lin He \& Chang-geng Shuai. Influence of magnetic conductive rubber on maglev actuator in active vibration control. Advanced Materials Research, 926-930, pp. 1365-1369, 2014 